\title{
Nacionalismo extractivo: déficit de rendición de cuentas en el sector petrolero ecuatoriano
}

Extractive Nationalism: Accountability Deficit in the Ecuadorian Oil Sector

Nacionalismo extrativista: déficit de prestação de contas no setor de petróleo equatoriano

\author{
Danny Ramírez Palacios \\ Facultad Latinoamericana de Ciencias Sociales (Sede Ecuador) \\ dramirezpalacios791@gmail.com
}

DOI: https://doi.org/10.32719/25506641.2019.5.7

Fecha de presentación: 19 de diciembre de 2018 • Fecha de aceptación: 17 de abril de 2019 Artículo de investigación

Licencia Creative Commons

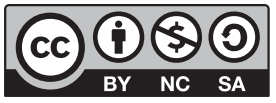




\section{Resumen}

El gobierno de la Revolución Ciudadana adoptó medidas para nacionalizar el petróleo, lo que generó mayores ingresos, pero, a la vez, afectó los controles democráticos del sector, en especial, la rendición de cuentas. Se plantea la pregunta: ¿Por qué la nacionalización de recursos generó un déficit en la rendición de cuentas? Se establece que, para lograr dicha nacionalización, se rediseñó la política petrolera -normas e instituciones-que provocaron el déficit. Se abordan las teorías del nacionalismo extractivo, y el diseño de políticas e instrumentos que permitan determinar las causas del déficit. Se concluye que la reconfiguración de la política y la introducción de nuevos instrumentos afectaron los controles democráticos del sector.

Palabras clave: Rendición de cuentas, control democrático, petróleo, nacionalismo extractivo.

JEL: H11 Estructura, ámbito y funcionamiento del sector público; H83 Administración pública; O38 Política pública.

\section{Abstract}

The government of the Citizen Revolution adopted measures to nationalize oil resources, generating higher revenues, but at the same time, affecting the democratic controls of the sector, especially accountability. The question posed is: Why this nationalization of resources generated a deficit in the rendering of accounts? In order to achieve this nationalization, the oil policy was redesigned, based on regulatory and institutional reforms, that caused the deficit. As an analytical framework, the theories of extractive nationalism are approached and a method that allows to determine the causes of the proposed deficit. $\mathrm{Tt}$ is concluded that the reconfiguration of the policy and the introduction of new instruments affected the democratic controls of the sector.

Keywords: Accountability, democratic controls, oil, extractive nationalism.

JEL: H11 Structure, scope and functioning of the public sector, H83 Public administration, O38 Public Policy.

\section{Resumo}

O governo da Revolução Cidadã adotó medidas para nacionalizar os recursos petrolíferos, gerando receitas mais elevadas, mas, afetando os controles democráticos do setor, especialmente a prestação de contas. Por que essa nacionalização de recursos gerou um déficit na prestação de contas?, para alcançar essa nacionalização, a política petroleira foi redesenhada, com base em reformas regulatórias e institucionais que causaram o déficit. Como um quadro analítico, as teorias do nacionalismo extrativo são abordadas juntamente com o rastreamento de processos. Conclui-se que a reconfiguração da política e a introdução de novos instrumentos afetaram os controles democráticos do setor.

Palavras-chave: Responsabilização, control democrático, petróleo, nacionalismo extrativista. JEL: H11 Estrutura, âmbito e funcionamento do setor público, H83 Administração pública, O38 Políticas públicas. 


\section{Introducción}

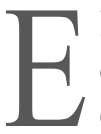

1 final del siglo XX estuvo fuertemente marcado por la tercera ola de democratización, ${ }^{1}$ la caída del comunismo y la adopción y propagación de instituciones democráticas en el mundo entero. Los Estados se vieron obligados a buscar una transformación hacia arriba (conformación de espacios supranacionales como la Unión Europea) y hacia abajo (descentralización y desconcentración de poder hacia organizaciones locales) para adaptarse a los nuevos cambios en el entorno. Al mismo tiempo, el nuevo entorno obligaba al Estado a transformarse también hacia afuera, con la inclusión de actores no estatales como las organizaciones no gubernamentales (ONG), sector privado, asociaciones, sindicatos, entre otros, revalorizando simbólicamente la sociedad civil y la participación de la ciudadanía.

La adopción del neoliberalismo en América Latina generó profundas consecuencias en la sociedad, que perduran hasta la actualidad. Los procesos democráticos han demostrado ser ineficientes y estructuralmente débiles como mecanismos de control sobre los funcionarios públicos (O’Donnell 1997). Algunos de estos mecanismos señalan que la transparencia y el control social son elementos clave para consolidar democracias más inclusivas, sin embargo, han sucumbido ante los elevados niveles de corrupción regional y ante la escasa normativa e institucionalidad.

La transparencia no funciona si no se logra insertar en la sociedad civil a la rendición de cuentas como mecanismo de control social de la gestión pública, a través de actividades de asociaciones de la sociedad civil, movimientos ciudadanos y medios de comunicación. En Ecuador, bajo el paradigma del Buen Vivir implementado en 2008, se garantizó la transparencia, el control social y la rendición de cuentas como una de las estrategias centrales

1. Se hace referencia a las olas democratizadoras de Samuel Huntington. 
para la profundización democrática y un elemento trascendental en la lucha contra la corrupción.

Al mismo tiempo, la economía ecuatoriana siguió dependiendo ampliamente de la industria petrolera, representando aproximadamente el 35\% del presupuesto general del Estado en 2015. La cantidad de ingresos monetarios que el sector produce para la economía nacional hace que se le atribuya una política específica para salvaguardar los recursos en favor del país, aun cuando este sector se ha caracterizado por el blindaje político al que ha sido sometido por los diferentes gobiernos de turno, situación que ha derivado en poca transparencia de la información y escaso acceso a temas sensibles por parte de la sociedad civil, medios de comunicación, o incluso, el mismo gobierno.

La actividad petrolera nacional en la década de 1990 fue condicionada a la inversión privada y a la disposición de grupos de poder para llevar el manejo del sector a su conveniencia; obviamente estas empresas recibían beneficios sustanciosos a base de los contratos otorgados. Pese a esto, el Estado como tal no veía incrementos sustanciales derivados de la actividad extractiva dentro de las arcas fiscales, así como la región amazónica, dueña del crudo, no veía desde el inicio de la actividad extractiva ningún tipo de rédito ni redistribución de las rentas petroleras en sus territorios (Acosta 2007).

Desde la implementación de las primeras leyes del sector hidrocarburífero (1918-1921), los gobiernos de turno han modificado en diversas ocasiones la Ley de Hidrocarburos del país; leyes que no solo han respondido a la necesidad de tecnificación y de captar la mayor cantidad de ingresos para el país, sino que han expresado los diversos intereses de los grupos de poder transnacional y político.

Muchos de los aspectos reformados generaron pérdidas al Estado, mediante las modalidades contractuales de servicios específicos, participación, alianzas operativas o estratégicas que no pagaban regalías, dejando desamparado al Estado, además de la rebaja de impuestos para las empresas del 44,4 al 25\% y luego al 15\% (Arauz 2004). Además de las pérdidas económicas, también se vulneraron derechos básicos de la población amazónica y se produjo un deterioro incalculable del medioambiente.

En 2005, Rafael Correa ocupaba el cargo de ministro de Economía en el gobierno de Alfredo Palacio, destacándose por la histórica decisión de modificar los beneficios derivados de la renta petrolera, pues para Correa los 
ingresos debían destinarse a la reinversión social y no al pago de la deuda externa. La medida adoptada permitió, por primera vez, que el país tome una posición más soberana sobre sus recursos (Le Calvez en Fontaine 2008). La administración de Palacio constituyó el comienzo de una política nacionalista que llegó a consolidarse durante el mandato de Rafael Correa, como presidente de los ecuatorianos desde el 15 de enero de 2007, al cual llegó como un outsider de la política, con ideas radicales de una nueva izquierda regional que adoptó el Socialismo del Siglo XXI como modelo.

Para Correa el nacionalismo de los recursos naturales buscaba cubrir algunos campos de acción, tal como los describe Haslam y Heidrich (2016). El nacionalismo extractivo se centra en: la maximización de los ingresos público; la afirmación del control estatal sobre el sector estratégico; y mejorar los efectos secundarios de la actividad extractiva, especialmente los que tienen que ver con el medioambiente. El modelo nacionalista implementado por Correa puede considerarse como radical, pues modificó la totalidad de la política petrolera mediante la inclusión de instrumentos que buscaron proteger los recursos para el país.

Los instrumentos incluidos en la nueva política petrolera, como la Reforma a la Ley de Hidrocarburos (EC 2011), en vigencia desde el 27 de julio de 2010 sin previo segundo debate legislativo; la Ley de Regalías (EC 2007), que elevó la participación del Estado en las ganancias extraordinarias del 50 al 99\%; y el Reglamento para la Entrega de Información Técnica, Económica y Ambiental de la industria petrolera, por citar algunos; condujeron a limitar los controles democráticos del sector petrolero, en especial la rendición de cuentas.

De esta manera, y a base de la relación entre el nacionalismo extractivo y la afectación a los controles democráticos, se plantea la pregunta de investigación de este artículo: ¿por qué la nacionalización de recursos generó un déficit en la rendición de cuentas? Como hipótesis se plantea que, para lograr nacionalizar los recursos, se rediseñó la política petrolera, a partir de reformas normativas e institucionales que generaron dicho déficit. Como marco analítico, se aborda los estudios sobre nacionalismo extractivo de Haslam y Heidrich (2016) y Fontaine y otros (2018); junto al método de rastreo de procesos, que permite determinar las causas del déficit planteado. Como principal fuente de evidencias, se estudian los instrumentos de la política 
petrolera, haciendo énfasis en la matriz NATO (nodalidad, autoridad, tesoro y organización) y el diseño de las políticas.

\section{Los controles democráticos en las políticas públicas}

Los controles democráticos han sido tratados como un tema cercano al estudio de la calidad y el desempeño de la democracia en los países, pues se considera que, para el goce de una buena democracia, es fundamental la existencia de un control diferente al del Estado. Los controles democráticos también se refieren a la "posibilidad de incidir sobre el curso de acción de una autoridad pública en cualquier instancia de los tres poderes (ejecutivo, legislativo y judicial), mediante agentes de control individuales o colectivos o mediante organizaciones civiles" (Isunza 2014, 11).

Como parte de los controles democráticos existentes, están los mecanismos de rendición de cuentas que encierran diversas dimensiones de análisis e interpretación; sin embargo, existen dos dimensiones básicas con las que se relaciona directamente: el answerability, entendido como la obligación de políticos y funcionarios de informar y justificar sus decisiones al público; y el enforcement, referido a la existencia de facultades legales de sanción mediante instituciones autónomas y externas (Hernández y Arciniegas 2011). La rendición de cuentas puede ser horizontal y vertical, según O’Donell (1998): horizontal cuando hace referencia a la situación en la que es el Estado el que se controla a sí mismo; y vertical cuando se desarrolla una relación de control que se da desde la sociedad hacia el Estado, es decir, cuando es la ciudadanía la que pone un límite o controla el accionar de los funcionarios públicos.

Más adelante, autores como Peruzzotti y Smulovitz plantearon que los procesos electorales tenían que complementarse con una sociedad civil activa y con el papel de los medios de comunicación autónomos. Para ello plantearon el control social como "un mecanismo de control vertical no electoral basado en las acciones que puedan llevar a cabo las asociaciones y también los movimientos conformados por ciudadanos, así como también en acciones mediáticas por parte de los medios de comunicación” $(2006,32)$. 
El control social representa una nueva forma de acción y cultura política, expresada, por un lado, en la presencia de una sociedad civil preocupada por lo público y que exige rendición de cuentas y, por el otro, el surgimiento de nuevas modalidades de representación de intereses y derechos colectivos que construye una representación diferente a la ejercida por los partidos políticos (Hernández y Arciniegas 2011).

Para Fontaine y otros (2018), el grado en que el nacionalismo de los recursos afecta los controles democráticos depende de las reformas implementadas por los gobiernos de cada país. Estas reformas pueden llegar a implementar modos jerárquicos de gobierno que tienen efectos negativos en los controles democráticos, especialmente en la rendición de cuentas cuando el ejecutivo concentra el poder sobre lo judicial y lo legislativo, lo que afecta la efectividad del equilibrio y las agencias asignadas. Además, afecta la responsabilidad social porque el gobierno controla la información y los grupos sociales a través de agencias específicas.

En algunos países de la región se ha evidenciado la nacionalización de los recursos naturales, en algunos más moderada como el caso peruano o colombiano, y, en otros casos, más radical, como en Venezuela, Bolivia o Ecuador. Es justamente esa radicalización de las ideas nacionalistas que puede llevar al sector a alejarse de la esencia de tener un adecuado control sobre el sector.

Los déficits de los controles democráticos provocaron un aumento del número de actores sociales demandantes de mayor participación y control sobre el Estado, como manera de generar presión para que funcionarios públicos y representantes elegidos justifiquen e informen constantemente sobre sus decisiones, y hacer frente a posibles sanciones cuando actúen de forma incorrecta o ilegal (Peruzzotti y Smulovitz 2006). Esta nueva responsabilidad de la sociedad es el resultado de una estrategia triple entre los medios de comunicación, la justicia y la sociedad.

\section{Metodología}

La metodología planteada en este artículo nace en el análisis del diseño de las políticas públicas y también de los instrumentos de política, temas que 
es necesario analizar de manera conjunta para lograr una mayor precisión metodológica sobre el problema de investigación.

\section{El diseño de políticas y los instrumentos de la política}

El diseño de políticas es una propuesta utilizada dentro del análisis de políticas públicas que hace su aparecimiento en la década de 1980 y que acompaña la reformulación del institucionalismo. Según Howlett $(2011,19)$, este marco explicativo permite entender "la configuración de las políticas públicas mediante la incorporación de los actores, las ideas y los intereses involucrados en la formulación e implementación del proceso de las políticas".

El argumento principal para abordar la utilización de este marco de análisis es la existencia de alguna conexión clara entre asumir la causa de un problema abordado, los instrumentos utilizados para remediar dicha situación y una comprensión un resultado deseable u óptimo (Peters 2015). El diseño de la política enfatiza esos vínculos y también la necesidad de dar importancia a las intervenciones políticas de manera más holística de lo que es común en el análisis de las políticas públicas.

Una de las versiones utilizadas en los últimos años en el diseño de políticas es la que hace hincapié en la aplicación y combinación de políticas e instrumentos que pueden implicarse en varios ámbitos de política. Este marco utiliza la tipología NATO de los instrumentos de Christopher Hood (1986) y Howlett y Ramesh (2003). Esta herramienta resume cuatro recursos básicos a través de los cuales los gobiernos detectan y efectúan acciones: nodalidad, evidencia una posición estratégica en el suministro de información (Hood 2007); autoridad, constituye el poder legal oficial y otras fuentes de legitimidad del gobierno; tesoro, son los activos del gobierno o bienes que pueden ser intercambiados libremente; y organización, configura un conjunto de personas con características y habilidades determinadas, materiales e inmateriales (Hood 2007; Hood y Margetts 2007).

La selección de un conjunto adecuado de instrumentos de política define la coherencia del diseño de política, ya sea de manera externa (entre objetivos y medios) o interna (entre los instrumentos) (Howlett y Rayner 2007). En su conjunto, estos instrumentos definen los contenidos sustanciales y pro- 
cedimentales de una política, en la medida en que afectan la distribución de bienes y servicios por parte del Estado, así como la regulación de las relaciones sociales dentro de las sociedades y entre la sociedad y el Estado (Howlett 2011).

En el contexto del diseño de la política, se puede definir las políticas públicas como "el resultado de los esfuerzos realizados por los gobiernos para alterar aspectos de su propio comportamiento social con el fin de llevar a cabo un fin o destino" (Howlett 2011, 19). El marco permite analizar la coherencia entre medios y objetivos de la acción del Estado, en función de diferentes grados o niveles de abstracción (Howlett y Cashore 2009). Los objetivos se refieren a las metas que buscan mediante la intervención y a las expectativas de los gobiernos al decidir si tomar o no alguna acción, mientras que los medios son las técnicas utilizadas para alcanzar esos objetivos planteados.

Tabla 1

Componentes del diseño de la política

\begin{tabular}{|c|c|c|c|c|}
\hline & & \multicolumn{3}{|c|}{ Niveles de la política } \\
\hline \multirow{3}{*}{$\begin{array}{l}\text { Componentes } \\
\text { de la política }\end{array}$} & & Paradigmático & Estratégico & Operativo \\
\hline & Objetivos & $\begin{array}{l}\text { Objetivos a nivel } \\
\text { de gobierno / } \\
\text { preferencias a } \\
\text { largo plazo. }\end{array}$ & $\begin{array}{l}\text { Áreas específicas, } \\
\text { direccionamiento para } \\
\text { cumplir objetivos a } \\
\text { mediano plazo. }\end{array}$ & $\begin{array}{l}\text { Micro requisitos apli- } \\
\text { cados en el terreno / } \\
\text { preferencias técnicas } \\
\text { a corto plazo. }\end{array}$ \\
\hline & Medios & $\begin{array}{l}\text { Dispositivos organ- } \\
\text { izativos que utiliza } \\
\text { el Estado. }\end{array}$ & $\begin{array}{l}\text { Selección de herrami- } \\
\text { entas o instrumentos. }\end{array}$ & $\begin{array}{l}\text { Calibración de instru- } \\
\text { mentos y ajustes de } \\
\text { la política. }\end{array}$ \\
\hline
\end{tabular}

Fuente: adaptado de Howlett y Cashore (2009).

Los niveles en que se desarrollan los objetivos y medios van desde el nivel más general o paradigmático de un modo de gobernanza al nivel más abstracto u operativo de un régimen de políticas en que se calibran los instrumentos, pasando por un nivel estratégico donde se desarrollan los estilos de implementación de la política (Howlett y Cashore 2009), tal como se muestran en la tabla 1. 
Según Howlett y Ramesh (2003), el concepto de instrumentos nace con el desarrollo de una taxonomía básica propuesta por Cushman en 1941, la cual se centra en la idea de que los gobiernos pueden optar por regular o no las actividades de la sociedad, y que si optan por la primera podían regular de manera coercitiva o no coercitiva. Luego de varios años, Kirschen (1964) intenta por primera vez clasificar a los instrumentos de la política económica, ofreciendo un análisis detallado de 64 tipos de instrumentos.

A pesar de los diversos avances en la manera de conceptualizar a los instrumentos, es Cristopher Hood en 1986 quien logra establecer una sencilla y sustentada taxonomía para agrupar la diversidad de instrumentos dentro de cuatro categorías que analizan la acción del gobierno a partir de la selección y utilización de instrumentos. En su estudio, asume la acción pública como variable dependiente y se interesa por la forma en que el Estado resuelve los problemas mediante el uso de instrumentos.

El modelo NATO, que se muestra en la tabla 2, se descompone en dos formas de intervención mediante instrumentos: la forma sustantiva constituye los instrumentos que alteran la distribución de bienes en las sociedades; y la procedimental, compuesta de aquellos instrumentos generadores de mecanismos para la interacción entre el Estado y la sociedad. Así, los gobiernos pueden manejar estos recursos para manipular a los actores de las políticas.

Los instrumentos de política son objeto de deliberación en todas las etapas del proceso de políticas y pueden afectar la definición del programa, los procesos de formulación, la implementación, la toma de decisiones y evaluación (Howlett 2011). Los instrumentos también se consideran medios no mecánicos de intervención, pero que tienen impactos políticos propios.

Para Linder y Peters (1993), los instrumentos son importantes en el proceso del diseño de políticas, ya que son las técnicas o medios a través del cual los Estados alcanzan los objetivos planteados. En el diseño se selecciona no solo el carácter más general del programa, sino también los instrumentos individuales que se utilizarán. Los instrumentos constituyen parte del contenido de una caja de herramientas que los gobiernos disponen para la creación de políticas públicas.

El diseño de políticas eleva el análisis y la práctica de la selección de instrumentos específicamente para la implementación, haciendo de su selección una preocupación clave dentro del marco explicativo. Mientras que, en 
Tabla 2

Tipología de los instrumentos de política de los recursos del Estado

\begin{tabular}{|c|c|c|c|c|c|c|}
\hline & & Nodalidad & Autoridad & Tesoro & Organización & \begin{tabular}{|c|} 
Dimensión \\
instrumental
\end{tabular} \\
\hline \multirow{4}{*}{$\begin{array}{l}\text { Objeti- } \\
\text { vos de } \\
\text { la polí- } \\
\text { tica }\end{array}$} & $\begin{array}{l}\text { Cambio en distri- } \\
\text { bución de bienes y } \\
\text { servicios (efectos). }\end{array}$ & $\begin{array}{l}\text { Asesoría, } \\
\text { capacita- } \\
\text { ción. }\end{array}$ & $\begin{array}{l}\text { Licencias, } \\
\text { certificacio- } \\
\text { nes, regula- } \\
\text { ciones. }\end{array}$ & $\begin{array}{l}\text { Subvención, } \\
\text { préstamos, } \\
\text { gastos fisca- } \\
\text { les. }\end{array}$ & \begin{tabular}{|l|} 
Burocracia, \\
administración. \\
pública-privada.
\end{tabular} & \multirow{2}{*}{$\begin{array}{l}\text { Sustantiva. } \\
\text { Afectan la } \\
\text { distribución } \\
\text { de bienes y } \\
\text { servicios en } \\
\text { las socieda- } \\
\text { des. }\end{array}$} \\
\hline & $\begin{array}{l}\text { Controlar la distri- } \\
\text { bución de bienes } \\
\text { y servicios (detec- } \\
\text { tores). }\end{array}$ & $\begin{array}{l}\text { Registros } \\
\text { informáti- } \\
\text { cos. }\end{array}$ & $\begin{array}{l}\text { Censos con- } \\
\text { sultores. }\end{array}$ & $\begin{array}{l}\text { Vigilancia de } \\
\text { recursos. }\end{array}$ & $\begin{array}{l}\text { Encuestas y } \\
\text { registros. }\end{array}$ & \\
\hline & $\begin{array}{l}\text { Promover interac- } \\
\text { ciones sociales y de } \\
\text { redes (positivo). }\end{array}$ & $\begin{array}{l}\text { Educación, } \\
\text { publicidad, } \\
\text { formación. }\end{array}$ & $\begin{array}{l}\text { Acuerdos, } \\
\text { tratados, } \\
\text { grupos ase- } \\
\text { soramiento. }\end{array}$ & $\begin{array}{l}\text { Financiación } \\
\text { intereses de } \\
\text { grupos. }\end{array}$ & $\begin{array}{l}\text { Audiencias, } \\
\text { reformas insti- } \\
\text { tucionales. }\end{array}$ & \multirow{2}{*}{$\begin{array}{l}\text { Procedimen- } \\
\text { tal. } \\
\text { Afectan las } \\
\text { relaciones so- } \\
\text { ciales en una } \\
\text { sociedad. }\end{array}$} \\
\hline & $\begin{array}{l}\text { Restringir interac- } \\
\text { ciones sociales y de } \\
\text { redes (negativo). }\end{array}$ & $\begin{array}{l}\text { Informa- } \\
\text { ción, pro- } \\
\text { paganda. }\end{array}$ & $\begin{array}{l}\text { Grupos o } \\
\text { asociaciones. }\end{array}$ & $\begin{array}{l}\text { Eliminación } \\
\text { de financia- } \\
\text { ción. }\end{array}$ & $\begin{array}{l}\text { Supresión de la } \\
\text { información. }\end{array}$ & \\
\hline
\end{tabular}

Fuente: adaptado de Howlett (2011).

el marco del neoinstitucionalismo sociológico los instrumentos de política no se observan como simples técnicas procedimentales para la solución de problemas, expresados casi siempre bajo una forma jurídica. Más bien, estos se definen como instituciones, porque constituyen un conjunto de reglas, normas y procedimientos que gobierna las interacciones y comportamientos de los actores y las organizaciones.

De esta forma el instrumento de acción pública es analizado como portador de valor, alimentado por una interpretación de lo social, constituyéndose en un dispositivo técnico y a la vez social que organiza unas relaciones sociales específicas entre los poderes públicos y sus destinatarios, en función de las representaciones y significaciones de las cuales son portadores (Lascoumes y Le Galès 2009).

En el diseño de la política petrolera ecuatoriana, se insertaron nuevos instrumentos de nodalidad, autoridad, tesoro y organización que fueron insertados en los niveles estratégico y operativo de la política con la finalidad de otorgar un cambio rápido a la política petrolera. Estos instrumentos no 
funcionaron como medios necesarios para el cumplimiento especifico de los objetivos que la política petrolera perseguía. Se intentó modificar o crear una nueva política, sin perder la esencia y el horizonte de la vieja política petrolera.

\section{Evidencia empírica y resultados de investigación}

Con la llegada de Rafael Correa al poder, el tema petrolero se posicionó nuevamente en la palestra pública, luego de dos décadas en las que no se había debatido nada relevante sobre el tema, pero ahora, con nuevos objetivos para la política petrolera, dotadas de una nueva corriente ideológica de la nueva izquierda regional que adoptó el Socialismo del Siglo XXI como modelo. La llegada de Correa al poder puede verse como una ventana de oportunidad (Kingdom 1984), útil para la reforma constitucional que llevó a cabo la Asamblea Constituyente, aprobada con $82 \%$ de respaldo, en Montecristi, provincia de Manabí.

Los nuevos objetivos que planteaba el gobierno de Correa se basaron en la preponderancia del rol del Estado, la elaboración de nuevas políticas de soberanía, la recuperación económica, el cambio de la matriz productiva y la inversión social. Estos objetivos lograron insertarse gracias a la mayoría representativa que su movimiento alcanzó en la Asamblea Nacional, lo que también amplió el rango y alcance de su poder político y de toma de decisiones (Orozco 2012).

Los nuevos objetivos para el sector petrolero fueron netamente nacionalistas, ya que el Estado se reserva el derecho de explotar y obtener el control mayoritario o la totalidad de los ingresos derivados de la actividad. La visión del sector se enfocó en negociar una relación más justa y equitativa entre el Estado y las empresas petroleras. Pero, a la par, este nacionalismo petrolero y sus consecuentes reformas permitirían al presidente implementar un modelo de gestión jerárquico en el sector, a raíz del fortalecimiento de un Estado con la capacidad de controlar un sector estratégico imprescindible para el gobierno.

Para conseguir el control de las instituciones, Correa implementó diversos instrumentos de organización. Inicialmente, reestructuró institucional- 
mente el sector petrolero favoreciendo el control político del Ejecutivo. Para ello se siguió la estructura institucional del Ejecutivo, partiendo de la Presidencia de la República, y, casi al mismo nivel, se apoya en dos instituciones clave, una para administrar y mejorar los procesos de la gestión pública (Secretaría Nacional de la Administración Pública), y la otra encargada de la planificación nacional (Secretaría Nacional de Planificación y Desarrollo).

A nivel ministerial, Correa decretó la creación de ministerios coordinadores que agrupen a los ministerios normales por su campo de acción. Dentro de los sectores estratégicos, se ordenó la división del anterior Ministerio de Energía, Minas y Petróleos, el 9 de julio de 2007, mediante Decreto Ejecutivo 475, y se creó por separado el Ministerio de Recursos Naturales no Renovable (MRNNR), que en 2009 sustituyó al Ministerio de Minas y Petróleos, para que este sea el ente ejecutor de las políticas y actúe como ente rector en materia hidrocarburífera. Con esto se transfirieron todas las facultades relacionadas con el sector petrolero, incluyendo el control de la Secretaria de Hidrocarburos ( $\mathrm{SH}$ ) y de todas las instituciones que tienen relación con el sector hidrocarburífero.

Esta división propició el manejo del sector estratégico petrolero, lo que permitió un control más personalizado sobre la institucionalidad del sector. Dentro de las diversas reformas a la Ley de Hidrocarburos, el art. 6 letra a) dio paso a la creación de la Secretaría de Hidrocarburos, para administrar y controlar las áreas y los contratos de operación, incluyendo la suscripción, a nombre del Estado, de todos los contratos de exploración y explotación, industrialización y transporte del crudo. Para controlar las actividades del sector se creó la Agencia de Regulación y Control Hidrocarburífero (ARCH), que tiene como tareas regular, controlar y fiscalizar las actividades técnicas y operacionales en las diferentes fases de la industria hidrocarburífera. La ARCH reemplaza a la Dirección Nacional de Hidrocarburos (DNH) que desapareció con esta ley. Otra de sus funciones es controlar la aplicación de la ley hidrocarburífera; auditar las actividades del sector; sancionar por el cometimiento de infracciones; solicitar caducidad de contratos, entre otros.

Lo común de estas instituciones es que, a base de sus criterios normativos, tienen una línea de comunicación directa con la Presidencia de la República, otorgándole al presidente un control sobre las decisiones del sector. Esto supuso un grave problema, pues, con la $\mathrm{ARCH}$, prácticamente todo se 
elabora y se gestiona dentro del sector porque aquí se define la política, se adjudican y firman los contratos con las empresas y tiene la potestad de auto fiscalizarse, desconociendo los artículos 204 y 213 de la Constitución (EC 2008), que establecen la obligación de garantizar entes de control independientes del Ejecutivo, participativos y especializados.

La total reestructuración trajo consigo una redistribución de responsabilidades que recayó sobre el vicepresidente Jorge Glas, a pedido del propio Rafael Correa. Esta designación fomentó el control total del Ejecutivo sobre el sector petrolero, debido también a que al sector se le otorgó independencia financiera, administrativa y operacional.

Otro de los instrumentos, esta vez de autoridad, que fue controversial y que sirvió para captar el poder político, fue la Reforma a la Ley de Hidrocarburos, que se analiza como el principal instrumento generador de la reconfiguración de la política petrolera, pues supuso la pauta para generar la mayoría de cambios que sufrió el sector. Se la considera controversial porque se aprobó sin debate legislativo, debido a una mayoría oficialista que favoreció las decisiones del Presidente en la Asamblea Nacional.

Luego del envío del proyecto de Ley Reformatorio a la Ley de Hidrocarburos y a la Ley de Régimen Tributario Interno, el Consejo de Administración Legislativa (CAL) resolvió calificar el proyecto como urgente en materia económica, estableciendo un plazo de 30 días para su debate y aprobación. El primer debate se desarrolló normalmente el 19 de julio de 2010, realizándose numerosas observaciones por parte de los legisladores. E1 25 de julio debía llevarse a cabo el segundo debate al proyecto de ley, pero no se concretó debido a que las autoridades de la Asamblea Nacional demoraron la convocatoria mediante jugadas políticas para no lograr el quórum necesario.

Ante esto, el entonces asambleísta Gilmar Gutiérrez² denunció que la bancada de PAIS dejó sin quórum al pleno legislativo, de manera premeditada, para evitar así la segunda instancia del debate. De esta manera, el 27 de julio de 2010 la reforma entró en vigencia por el ministerio de la ley

2. "Partido Sociedad Patriótica exige a Jefe de Estado que dé nombres de legisladores que recibieron presiones para oponerse a Ley de Hidrocarburos", Ecuador Inmediato, 27 de julio de 2010. 〈http://www.ecuadorinmediato.com/Noticias/news_user_view/psp_exige_a_jefe_de_ estado_que_de_nombres_de_legisladores_que_recibieron_presiones_para_oponerse_a_ley_ de_hidrocarburos-130955>. 
mediante su publicación en el Registro Oficial 244, suplemento del 27 de julio de 2010. Como reformas complementarias se incluyeron cambios en el porcentaje de la distribución de utilidades a los trabajadores, con el fin de destinar un porcentaje a la inversión social en los territorios donde se lleve a cabo la actividad.

Analizando los instrumentos de nodalidad o información, se hace énfasis de la limitada información que brindaba el sector para la sociedad civil, la cual se concentraba en pocas agencias. Para determinar la evidencia necesaria, se realizó una búsqueda exhaustiva de información en las páginas web institucionales del sector petrolero para determinar qué tipo de información posee cada una. Además, se realizaron solicitudes de información pública sobre datos del sector para corroborar lo mencionado en esta investigación, y que fueron realizadas a Petroecuador y al ministerio del ramo, sin tener respuesta satisfactoria en un plazo de al menos seis meses, hasta el cierre de la investigación.

Mediante el rastreo web de información, se pudo determinar que la Sección de Hidrocarburos posee información estadística desde el año 2001 al 2014 sobre producción, transporte, comercialización, exportaciones e industrialización del recurso petrolero. Existen además contratos desde 2010 hasta 2016, pero solo de algunos bloques petroleros y los que constan en el registro electrónico carecen de la información financiera. La mayoría de estos contratos son los que migraron a la modalidad prestación de servicios, pero no consta información de los contratos de los bloques 31 y 43, dos de los bloques petroleros más importantes de la Amazonía.

Por otro lado, la empresa pública Petroamazonas es la encargada de mantener información de las otras etapas de la cadena de valor del petróleo; en esta institución la información no es pública y en su web institucional constan escasos informes de auditoría de contratos y algunas evaluaciones de impacto de bloques menores. En la sección contratos de la web solo existen documentos normativos y procedimentales para contratar con la empresa.

$\mathrm{El}$ ente regulador, $\mathrm{ARCH}$, posee escasa información sobre producción mensual del petróleo de 2016 y 2017, y escasa información sobre la perforación de bloques. También se mencionan controles realizados por la entidad, pero los resultados no son públicos. El Ministerio de Hidrocarburos posee 
decretos, acuerdos ministeriales y leyes, pero no tiene información técnica de ningún tipo.

Si bien la información del sector petrolero se concentra en pocas agencias, esto no significa que la información esté disponible en las páginas web institucionales para el acceso público. Además, las solicitudes de información presentadas no tuvieron respuesta y algunas fueron denegadas y obstaculizadas por complejas trabas burocráticas.

Pese a la existencia de un reglamento que regula la información de la industria petrolera, establecido mediante Acuerdo Ministerial 107, Registro Oficial 298 de 19 de marzo de 2008, la misma es limitada e incompleta. El reglamento establece el procedimiento para la entrega y reproducción de la información técnica, económica y ambiental relacionada con cualquier fase de la industria petrolera; sin embargo, el artículo 2 de dicha norma señala que la información solicitada se entregará solamente a personas naturales o jurídicas, nacionales o extranjeras que estén interesadas en realizar inversiones, o presentar proyectos para el desarrollo de actividades hidrocarburíferas, limitando la solicitud de información por parte de actores que son ajenos a la actividad petrolera en el país.

La normativa que rige el acceso a la información en el Ecuador es la Ley Orgánica de Transparencia y Acceso a la Información (LOTAIP) (EC 2004), que constituyó los inicios para garantizar transparencia en el manejo de la información pública. No obstante, esta ley no recoge aspectos concretos referentes a la industria hidrocarburífera nacional, ni especifica la periodicidad del reporte de información y tampoco las instituciones encargadas del manejo de la misma.

Finalmente, el instrumento de tesoro analizado en este trabajo se refiere a las nuevas condiciones contractuales que las empresas petroleras privadas aceptaron bajo presión del presidente y su gobierno. Para generar dicha presión, el gobierno se valía de los recursos del Estado para crear campañas de amenazas constantes hacia las petroleras, con la finalidad de que estas modifiquen sus contratos vigentes.

Esta renegociación de los contratos petroleros tuvo que ver con el cambio del modelo de contratación de las compañías petroleras privadas. Los contratos migraron de un formato de participación, en que las compañías recibían una parte de la producción de crudo, a uno de prestación de servicios 
con tarifa, que aseguraba la propiedad estatal sobre el total de la producción y que reconocía a las compañías una tarifa fija por sus costos e inversiones en la operación de los diferentes campos; con esto la participación del Estado se incrementaría hasta el $70 \%$ de la producción.

Con la nueva modalidad se esperaba mejorar la participación del Estado en la renta petrolera, atraer nueva inversión extranjera para actividades de riesgo exploratorio, incrementar las reservas de petróleo y subir la producción de los bloques privados. Se otorgó un plazo de 180 días para que las petroleras lleguen a un acuerdo en la renegociación de sus contratos. Como resultado, se renegociaron 14 de 23 contratos, y el Estado ecuatoriano recibió por ingresos adicionales US \$2.795 millones de dólares. ${ }^{3}$

Según el Banco Central del Ecuador, de 2000 a 2010, los ingresos provenientes del petróleo fueron de US \$ 26.652 millones de dólares, y solamente en el año 2010, año de las principales reformas, los ingresos del petróleo fueron de 9.673 millones; llegando al año 2014 a un valor de US \$ 14.107 millones de dólares, año en que los precios del petróleo se mantuvieron altos.

Como reformas complementarias se incluyeron cambios en el porcentaje de la distribución de utilidades a los trabajadores. Se dispuso que estos reciban el $3 \%$ del porcentaje de utilidades y el $12 \%$ restante será pagado al Estado para destinarlo en proyectos de inversión social en salud y educación (art. 94 de la Ley de Hidrocarburos), a través de los Gobiernos Autónomos Descentralizados.

Finalmente, los casos de corrupción del sector petrolero han demostrado que la falta de información del sector es un arma de doble filo, que dio paso a la falta de control y de rendición de cuentas adecuada por parte de las autoridades a cargo del sector, pues prueba de ello son los procesos judiciales sobre dos exgerentes de la estatal Petroecuador y sobre un exministro de Hidrocarburos, que finalmente los llevaron a prisión por una serie de irregularidades con el manejo de fondos petroleros.

3. (EC) Ministerio de Recursos Naturales No Renovables. 2012. "Informe de Gestión”. 


\section{Conclusiones}

El déficit de control democrático y de rendición de cuentas persiste debido, primeramente, al diseño de la política petrolera ecuatoriana, y, segundo, al excesivo control político que el gobierno de Rafael Correa logró implementar en el país. Así mismo, las reformas normativas e institucionales del sector dieron paso a una reconfiguración de la política petrolera ecuatoriana, procesos que al largo plazo debilitaron al sector; prueba de ello son los casos de corrupción que se destaparon con el fin de la Revolución Ciudadana.

El sector petrolero se ha caracterizado por poseer información de escasa accesibilidad, dispersa y compleja, dificultando conocer las actividades y etapas de su gestión y los impactos que ha generado a nivel económico y ambiental. La esencia de la política petrolera anterior nunca se perdió y solo se calibraron e introdujeron algunos nuevos instrumentos, afectando el diseño de la política como tal, evitando el cumplimiento de los objetivos para la misma.

El excesivo control político por parte del Estado jamás ha favorecido la democracia ni el control de la sociedad; por el contrario, ha deteriorado los mecanismos de participación ciudadana. El último gobierno supo controlar totalmente los poderes del Estado y con ello también se apoderó de las instituciones de control, lo que parcializó muchas decisiones que afectaron el control social en Ecuador.

Para que exista un eficiente control social es necesario que las competencias de los actores se definan claramente y que estos actúen alejados de ideologías políticas y en beneficio de la sociedad. Es necesario la presencia de nuevos actores públicos, privados y de la sociedad civil, para ser abanderados del control social y del diseño de las políticas en el Ecuador, además de los actores que se ven afectados por las decisiones del Estado.

\section{Referencias}

Acosta, Alberto. 2007. La maldición de la abundancia. Quito: Abya-Yala.

Aráuz, Luis Alberto. 2004. "Contratación petrolera ecuatoriana". En Guillaume Fontaine, Petróleo y desarrollo sostenible en Ecuador. Las apuestas, 25-32. Quito: FLACSO. 
Cushman, Robert. 1941. Comparative Public Policy. Nueva York.

EC. 2007. Decreto Ejecutivo 662. Registro Oficial 966, 12 de marzo.

---. 2008. Constitución de la República del Ecuador. Registro Oficial 449, 20 de octubre.

---. 2010a. Ley de hidrocarburos. Registro Oficial 711, 15 de noviembre.

---. 2010b. Ley Reformatoria a la Ley de Hidrocarburos y a la Ley de Régimen Tributario Interno. Registro Oficial 244, Suplemento, 27 de julio.

---. 2010c. Ministerio de Recursos Naturales No Renovables. “Informe de Gestión”. 〈https:// www.proecuador.gob.ec/exportado\%20res/publicaciones/monitoreo-de-exportaciones/>.

Fontaine, Guillaume. 2008. "La investigación latinoamericana ante las políticas energéticas". En Fontaine Guillaume y Puyana Alicia, edits., La guerra del fuego. Políticas petroleras y crisis energética en América Latina, 6-10. Quito: FLACSO.

---, Iván Narváez y Bayron Paz. 2018. "Explaining Public Accountability Deficit in Extractive Policies: The Ecuadorian Case”. The Extractive Industries and Society 5, No. 1: 190-200.

Haslam, Paúl, y Pablo Heidrich. 2016. "From Neoliberalism to Resource Nationalism: States, Firms and Development”. En Paúl Haslam y Pablo Heidrich, edits., The Political Economy of Natural Resources and Development: From Neoliberalism to Resource Nationalism, 1-32. Londres: Routledge.

Hernández, Andrés, y Elizabeth Arciniegas. 2011. "Aproximación conceptual: el accountability desde una perspectiva comparada en América Latina: estudios de caso". En Andrés Hernández y Elizabeth Arciniegas, comps., Experiencias de accountability horizontal y social en América Latina: estudios de caso comparados en São Paulo, México DF, Caracas y Bogotá, 21-48. Bogotá: Uniandes.

Hood, Christopher. 1986. The Tools of Government. Chatham: Chatam House.

---. 2007. "Intellectual Obsolence and Intelectual Makeovers: Reflections on The Tools of Government After Two Decades". Governance: An International Journal of Policy, Administration, and Institutions 20, No. 1: 127-144.

---, y Helen Margetts. 2007. The Tools of Government in the Digital Age. Nueva York: Palgrave Macmillan.

Howlett, Michael. 2011. Designing Public Policies: Principles and Instruments. Nueva York: Routledge.

---, y M. Ramesh. 2003. Studying Public Policy: Policy Cycles and Policy Subsystems. Oxford: Oxford University Press.

---, y Rayner Jeremy. 2007. "Design Principles for Policy Mixes: Cohesion and Coherence in New Governance Arrangements". Policy and Society, No. 42: 73-89.

---, y Cashore Benjamin. 2009. “The Dependent Variable Problem in the Study of Policy Change: Understanding Policy Change as a Methodological Problem”. Journal of Comparative Policy Analysis 11, No. 1: 33-46.

Isunza Vera, Ernesto. 2014. "Controles democráticos no electorales en perspectiva comparada: un avance desde el análisis relacional". Documento de trabajo. Encontro Anual da ANPOCS. Consulta: enero de 2019. 〈https://anpocs.com/index.php/papers-38-encon- 
tro/gt-1/gt08-1/8888-controles-democraticos-no-electorales-en-perspectiva-comparada-un-avance-desde-el-analisis-relacional/filè.

Kirschen, Étienne Sadi. 1964. Economic Policy in Our Time: General Theory. Amsterdam: McNally.

Lascoumes, Pierre, y Patrick Le Galès. 2009. "Instrumento". En Laurie Boussaguet, Jacquot Sophie y Pauline Ravinet, dirs., Diccionario de políticas públicas, 514. Bogotá: Universidad Externado de Colombia.

Linder, H. Stephen, y Guy Peters. 1993. "Instrumentos de gobierno: percepciones y contextos”. Gestión y Políticas Públicas 37, No. 149: 34-40.

O'Donnell, Guillermo. 1997. Contrapuntos. Ensayos escogidos sobre autoritarismo y democratización. Buenos Aires: Paidós.

Orozco, Mónica. 2012. "Una política sin rumbo: el caso de la política petrolera ecuatoriana 2005-2010”. Tesis de maestría en Ciencias Sociales con mención en Gobernanza Energética. FLACSO Ecuador.

Peruzzotti, Enrique, y Catalina Smulovitz. 2006. Enforcing the Rule of Law. Social Accountability in the New Latin American Democracies. Pittsburgh: University of Pittsburgh Press.

Peters, Guy. 2015. Advanced Introduction to Public Policy. Cheltenham: Elgar. 